\title{
STUDIES ON INTERMEDIATE CARBOHYDRATE METABOLISM IN MULTIPLE SCLEROSIS
}

\author{
BY \\ B. MCARDLE,* I. C. K. MACKENZIE, and G. R. WEBSTER \\ From the Department of Chemical Pathology and of Neurology, Guy's Hospital Medical School, London
}

The possibility of a defect in pyruvate metabolism in multiple sclerosis was first investigated in detail by Jones, Jones, and Bunch (1950). These workers found that the mean fasting blood pyruvate level of 40 patients with multiple sclerosis in relapse was significantly greater than that of 30 control subjects and that there was also in these patients a rather greater rise after the ingestion of glucose. A group of 38 patients in remission showed only a slight elevation of the fasting blood pyruvate and a normal response to glucose ingestion. Ervenich (1952, 1953) and Šercl and Johnová (1956) also reported that the fasting pyruvate level was frequently raised in this disease, but Bauer (1956), Henneman, Altschule, Goncz, and Alexander (1954) and Jeanes and Cumings (1958) either found the fasting level normal, or raised in only a small proportion of cases. After glucose ingestion, however, Jeanes and Cumings (1958) found an abnormal rise in the blood pyruvate level in 15 of their 26 active and in two of their seven inactive cases.

These reports suggest the possibility of an abnormality of pyruvate degradation in multiple sclerosis and some further evidence for this is provided by the studies of two other acids of the Krebs cycle, though here too there is a further conflict of findings. Henneman et al. (1954) and Bauer (1956), the only workers to employ specific methods for the determination of pyruvate, both found the fasting pyruvates abnormal, but the former found the mean fasting level for $\alpha$-ketoglutarate raised, the latter within the normal range. Only a small number of patients, however, were investigated. Henneman et al. (1954) also found in their six cases of active multiple sclerosis a rise in the plasma citrate level following glucose ingestion instead of the usual fall. A rise was also observed by Jeanes and Cumings (1958) at some point after glucose was ingested in nine out of 14 cases.

It is clear therefore that there is a considerable divergence of view as to the presence, the nature,

* Member of external scientific staff, Medical Research Council. and the significance of a defect of the Krebs cycle in this disease. In view of the importance of oxidative metabolism as the main source of energy both in the normal activity of nervous tissue and in the maintenance of the myelin sheath, a further investigation of these points seemed indicated. Forty-one patients with multiple sclerosis have therefore been studied and in 17 of these specific methods for the estimation of $\alpha$-keto acids have been employed.

\section{Experimental Details}

Clinical Material.-Forty-one patients with multiple sclerosis were investigated. Sixteen were male and 25 female, their ages ranging from 19 to 60 with a mean of 38.4 years, and the duration since the first clinically recognizable episode ranging from six weeks to 26 years with a mean of $7 \cdot 2$ years. They were all fully investigated in hospital and have been followed for a sufficient length of time to establish the diagnosis beyond reasonable doubt. Cases with fever or infection were not included.

Methods. - The response of the blood pyruvate and $\alpha$-ketoglutarate and of the plasma citrate to the ingestion of glucose has been carried out by a procedure previously described by Joiner, McArdle, and Thompson (1950). In the majority of patients, this procedure, which will be referred to henceforth as a "pyruvate tolerance test", was carried out after the patients had been in hospital for three or more days. In the other cases and in the healthy control subjects the initial blood sample was not taken until the subject had been resting on a couch for 30 to 40 minutes.

Venous blood samples were taken rapidly with the minimum of stasis and with particular care to avoid any activity of the forearm or hand muscles for some minutes before the venepuncture. A proportion of the blood was immediately deproteinized in $5 \%$ metaphosphoric acid, the actual amount being later measured by weighing. The remainder of the blood was heparinized, the plasma separated after centrifugation, deproteinized with $10 \%$ trichloracetic acid and the filtrate kept in a refrigerator, the citric acid in it being determined within one or two days. The $\alpha$-keto acid estimations were started immediately. Cerebrospinal fluid was collected in a tube and immediately decanted into metaphosphoric acid. 
Pyruvate in blood was determined by the method of Friedemann and Haugen (1943) in all instances. In addition, a paper chromatographic technique (McArdle, 1957) has been used in some patients for estimating the levels of pyruvate and $\alpha$-ketoglutarate in blood and cerebrospinal fluid. Plasma citrate was measured by a modification (McArdle, 1955) of the method of WeilMalherbe and Bone (1949).

\section{Results}

Pyruvate Metabolism.-The blood pyruvate, as estimated by the Friedemann and Haugen (1943) technique, has been followed in 41 cases of multiple sclerosis and in 20 normal subjects. The mean levels are presented in Table I, but only the results of the first test are included where more than one test was performed on any one patient.

When the levels in the patients are compared with the control values at comparable times, a significant difference was found only at $90 \mathrm{~min}$. Although the value at $60 \mathrm{~min}$. was almost identical with that at $90 \mathrm{~min}$., the difference between patients and controls at $60 \mathrm{~min}$. was not significant owing to wide scatter.

Only five patients $(12 \%)$ had abnormally high fasting values, that is, greater than the mean +2 S.D. of the 20 control subjects, but $18(44 \%)$ had abnormal values at 60 and/or $90 \mathrm{~min}$. after glucose, though in six of these $(15 \%)$ the rise was less than $0 \cdot 1 \mathrm{mg}$. above the normal range. In eight $(19.5 \%)$ the abnormality was well marked, the level rising above $1.5 \mathrm{mg} . / 100 \mathrm{~g}$. If all the tests (57) are included the proportion of patients showing elevated levels rises when fasting to $24 \%$ and after glucose to $54 \%$, the maximum value being above $1.5 \mathrm{mg}$. $/ 100 \mathrm{~g}$. in $24 \%$.

The fasting levels of those patients showing an abnormal response to glucose have been compared with those of the remainder. Those with a normal response had a mean fasting level of 0.58 whereas those with an excessive rise had a mean level of $0.71 \mathrm{mg} . / 100 \mathrm{~g}$.

Pyruvate Levels as Estimated by Paper Cromatography.-The same abnormality in pyruvate meta- bolism has been found in the 17 patients with multiple sclerosis whose blood has been examined by the chromatographic technique. The results, together with those obtained by the Friedemann and Haugen technique on the same protein-free filtrates, are given in Table 1. Pyruvate tolerance tests had previously been carried out in four of these patients by the latter technique. Also included in this table are the values obtained with the chromatographic procedure in the group of 20 healthy subjects.

The similarity of the response to glucose found by the two techniques in the patients and the control group can be seen in Table I, though the normal fasting value of $0.48 \mathrm{mg} . / 100 \mathrm{~g}$. is only $79 \%$ of that given by the Friedemann and Haugen method. This lower percentage agrees well with the figure of $84 \%$ found by Bauer (1956) using a specific enzyme method for estimating blood pyruvate. The mean values at 60 and $90 \mathrm{~min}$. after the ingestion of glucose are 0.74 and $0.73 \mathrm{mg} . / 100 \mathrm{~g}$. respectively. Values above the mean and 2 S.D., that is, above $0.62,1.08$, and $1.03 \mathrm{mg}$. pyruvic acid/100 g. at 0,60 , and 90 min. respectively, have been taken as being significantly above the normal range.

The mean fasting value of $0.44 \mathrm{mg} . / 100 \mathrm{~g}$. in the cases of multiple sclerosis is almost identical with that of the control group and in only one patient was the value $(0.78 \mathrm{mg} . / 100 \mathrm{~g}$.) raised significantly $\unrhd$ above the upper normal limit. The mean levels at 60 and $90 \mathrm{~min}$. were 0.97 and 0.95 respectively. These are significantly raised above the normal means (P less than 0.025) and agree with the findings by the Friedemann and Haugen technique. In seven patients $(41 \%)$ the 60 and/or the $90 \mathrm{~min}$. values were above the normal range, the Friedemann and Haugen values also being abnormal in these cases but not in the others. The rise in pyruvate was considerably above $1.30 \mathrm{mg} . / 100 \mathrm{~g}$. in five of these seven cases.

$\alpha$-Ketoglutarate. - It can be seen from Table II that there are no significant differences in the mean $\alpha$-ketoglutarate levels between the normal control

TABLE I

EFFECT OF $100 \mathrm{~g}$. GLUCOSE ON THE LEVELS OF BLOOD PYRUVATE IN NORMAL SUBJECTS AND PATIENTS WITH MULTIPLE SCLEROSIS

\begin{tabular}{|c|c|c|c|c|c|c|}
\hline \multirow{2}{*}{\multicolumn{2}{|c|}{ Method }} & \multirow{2}{*}{ Subjects } & \multirow{2}{*}{ Number } & \multicolumn{3}{|c|}{ Mean Blood Pyruvate Level (mg./100 g.) } \\
\hline & & & & 0 min. & $60 \mathrm{~min}$. & $90 \mathrm{~min}$. \\
\hline \multirow[t]{2}{*}{$\begin{array}{l}1 \\
2 \\
3 \\
4\end{array}$} & $\begin{array}{l}\text { Friedmann and Haugen } \\
\text { Chromatography }\end{array}$ & $\begin{array}{l}\text { Normal } \\
\text { Multiple sclerosis } \\
\text { Normal } \\
\text { Multiple sclerosis }\end{array}$ & $\begin{array}{l}20 \\
41 \\
20 \\
17\end{array}$ & $\begin{array}{l}0.62(0.11)^{*} \\
0.637(0.224) \\
0.48(0.07) \\
0.44(0.12)\end{array}$ & $\begin{array}{l}0.91(0 \cdot 19) \\
1.112(0.525) \\
0.74(0 \cdot 17) \\
0.97(0 \cdot 38)\end{array}$ & $\begin{array}{l}0.88(0.19) \\
1.107(0.304) \\
0.73(0 \cdot 15) \\
0.95(0.32)\end{array}$ \\
\hline & $\begin{array}{l}2 \text { v. } 1 \\
4 \text { v. } 3\end{array}$ & & & $\begin{array}{c}\mathbf{P} \text { values } \dagger \\
\text { - }\end{array}$ & 0.025 & $\begin{array}{l}0.01 \\
0.025\end{array}$ \\
\hline
\end{tabular}

*S.D. in brackets.

†Probability that the differences are due to chance. 
TABLE II

EFFECTS OF $100 \mathrm{~g}$. GLUCOSE ON $\alpha$-KETOGLUTARATE METABOLISM IN 20 NORMAL SUBJECTS AND IN PATIENTS WITH MULTIPLE SCLEROSIS

\begin{tabular}{|c|c|c|c|c|c|}
\hline & \multirow{2}{*}{ Subjects } & \multirow{2}{*}{ Number } & \multicolumn{3}{|c|}{ Mean Blood $\alpha$-Ketoglutarate (mg./100 g.) } \\
\hline & & & $0 \mathrm{~min}$. & $60 \mathrm{~min}$. & $90 \mathrm{~min}$. \\
\hline \multirow[t]{2}{*}{$\begin{array}{l}1 \\
2 \\
3 \\
4\end{array}$} & $\begin{array}{l}\text { Normal } \\
\text { Multiple sclerosis } \\
\text { Total } \\
\text { Group A } \\
\text { Group B }\end{array}$ & $\begin{array}{r}20 \\
17 \\
10 \\
7\end{array}$ & $\begin{array}{l}0.15(0.044)^{*} \\
0.144(0.048) \\
0 \cdot 123(0.025) \\
0.173(0.054)\end{array}$ & $\begin{array}{l}0.167(0.062) \\
0.179(0.075) \\
0.137(0.042) \\
0.237(0.072)\end{array}$ & $\begin{array}{l}0.167(0.06) \\
0.185(0.085) \\
0.137(0.046) \\
0.254(0.075)\end{array}$ \\
\hline & $\begin{array}{l}2 \text { v. } 1 \\
3 \text { v. } 1 \\
4 \text { v. } 3\end{array}$ & & $\begin{array}{c}\mathbf{P} \text { valuest } \\
0.05\end{array}$ & $\begin{array}{l}0.025- \\
0.01\end{array}$ & $\begin{array}{l}0.01 \\
0.01\end{array}$ \\
\hline
\end{tabular}

*S.D. in brackets. †Probability that the differences are due to chance.

TABLE III

SEX DIFFERENCES IN FASTING LEVEL OF BLOOD $\alpha$-KETOGLUTARATE IN NORMAL SUBJECTS AND IN PATIENTS WITH MULTIPLE SCLEROSIS

\begin{tabular}{|c|c|c|c|c|c|c|}
\hline \multirow{2}{*}{\multicolumn{2}{|c|}{ Subjects }} & \multirow{2}{*}{ Sex } & \multirow{2}{*}{ Number } & \multicolumn{3}{|c|}{ Mean Blood $\alpha$-Ketoglutarate (mg./100 g.) } \\
\hline & & & & $0 \mathrm{~min}$. & $60 \mathrm{~min}$. & $90 \mathrm{~min}$. \\
\hline \multirow[t]{2}{*}{$\begin{array}{l}1 \\
2 \\
3 \\
4 \\
5 \\
6\end{array}$} & $\begin{array}{l}\text { Normals } \\
\text { Normals } \\
\text { Multiple sclerosis } \\
\text { Multiple sclerosis } \\
\text { Combined } \\
\text { Combined }\end{array}$ & $\begin{array}{l}\mathbf{M} \\
\mathbf{F} \\
\mathbf{M} \\
\mathbf{F} \\
\mathbf{M} \\
\mathbf{F}\end{array}$ & $\begin{array}{r}12 \\
8 \\
7 \\
10 \\
19 \\
18\end{array}$ & $\begin{array}{l}0.135(0.044)^{*} \\
0.123(0.039) \\
0.123(0.021) \\
0.158(0.056) \\
0.131(0.037) \\
0.164(0.05)\end{array}$ & $\begin{array}{l}0.158(0.05) \\
0.187(0.048) \\
0.14(0.048) \\
0.206(0.083) \\
0.152(0.052) \\
0.198(0.069)\end{array}$ & $\begin{array}{l}0.158(0.048) \\
0.187(0.044) \\
0.146(0.056) \\
0.212(0.093) \\
0.153(0.052) \\
0.198(0.069)\end{array}$ \\
\hline & 6 v. 5 & & & $\underset{0.05}{P \text { values }}$ & 0.05 & 0.05 \\
\hline
\end{tabular}

*S.D. in brackets. †Probability that the differences are due to chance.

group and the multiple sclerosis patients, either in the fasting state or at 60 and 90 min. after ingestion of glucose. Furthermore, only very small elevations above the fasting level were found at 60 and $90 \mathrm{~min}$. However, if the multiple sclerosis patients are subdivided into two groups, group A comprising patients in whom there was a normal response in blood pyruvate level after glucose, and group B those in whom this response was abnormal, it can be seen that those who had an abnormal pyruvate response also had significantly raised values for $\alpha$-ketoglutarate. When the levels in group B are compared with the corresponding figures for group A even more marked differences are found, since the mean fasting $\alpha$-ketoglutarate level in group $\mathrm{A}$ is lower than that of the control group, with a normal increment after glucose. The explanation of the low fasting level in group $\mathbf{A}$ is obscure, and its interpretation is complicated by the finding (Table III) that the fasting level of the females in the control group is greater than that of males. This sex difference is not statistically significant, but a similar trend is apparent also in the patients, and if patients and control subjects are combined there is then a significant difference in the fasting levels in the two sexes. However, no sex differences were apparent in the control series in the increments in $\alpha$-ketoglutarate level following glucose.

TABLE IV

EFFECT OF $100 \mathrm{~g}$. OF GLUCOSE ON LEVEL OF PLASMA CITRATE IN 20 NORMAL SUBJECTS AND IN PATIENTS WITH MULTIPLE SCLEROSIS

\begin{tabular}{|c|c|c|c|c|c|}
\hline \multirow{2}{*}{\multicolumn{2}{|c|}{ Subjects }} & \multirow{2}{*}{ Number } & \multicolumn{3}{|c|}{ Mean Plasma Citrate (mg./100 ml.) } \\
\hline & & & $0 \mathrm{~min}$. & $60 \mathrm{~min}$. & $90 \mathrm{~min}$. \\
\hline$\frac{1}{2}$ & $\begin{array}{l}\text { Normals } \\
\text { Multiple sclerosis }\end{array}$ & 20 & $2 \cdot 18(0 \cdot 32)^{*}$ & $2 \cdot 12(0 \cdot 33)$ & $1.98(0.26)$ \\
\hline $\begin{array}{l}3 \\
4\end{array}$ & $\begin{array}{l}\text { Total } \\
\text { Group A } \\
\text { Group B }\end{array}$ & $\begin{array}{r}17 \\
10 \\
7\end{array}$ & $\begin{array}{l}1.86(0.60) \\
2.15(0.53) \\
1.45(0.45)\end{array}$ & $\begin{array}{l}1.78(0.56) \\
2.01(0.46) \\
1.41(0.53)\end{array}$ & $\begin{array}{l}1.67(0.50) \\
1.89(0.48) \\
1.36(0.35)\end{array}$ \\
\hline & $\begin{array}{l}1 \text { v. } 2 \\
1 \text { v. } 4 \\
3 \text { v. } 4\end{array}$ & & $\begin{array}{l}P \text { values } \dagger \\
0.01- \\
0.025\end{array}$ & $\begin{array}{l}0.05 \\
0.01 \\
0.05\end{array}$ & $\begin{array}{l}0.025 \\
0.01 \\
0.05\end{array}$ \\
\hline
\end{tabular}

*S.D. in brackets.

+Probability that the differences are due to chance. 
Citrate Metabolism. - The only significant abnormality (Table IV) in the citrate metabolism of the multiple sclerosis patients is the relatively low value for the fasting level of plasma citrate. This was due to the findings in those patients with an abnormal rise in pyruvate after glucose (group B), for in these seven cases the mean fasting value was $1.45 \mathrm{mg} . / 100 \mathrm{ml}$. as compared with the normal value of $2.15 \mathrm{mg} . / 100 \mathrm{ml}$. found in the remaining patients. Our patients as a whole showed a fall of citrate at $90 \mathrm{~min}$. that was only slightly less than that of the control series, though the fall was least in those patients having an abnormal pyruvate response to glucose and a low fasting citrate.

Cerebrospinal Fluid.-The $\alpha$-keto acids in the cerebrospinal fluid were determined by the chromatographic method in 12 patients with multiple sclerosis. The mean level of pyruvate was $0.86 \mathrm{mg}$./ $100 \mathrm{~g}$. (range $0 \cdot 65-1 \cdot 22$ ), and that of $\alpha$-ketoglutarate was less than $0.02 \mathrm{mg} . / 100 \mathrm{~g}$. (range, trace-0.025). Comparison with normal cerebrospinal fluid has not been possible, but the mean level for pyruvate is rather lower than the $0.96 \mathrm{mg} . / 100 \mathrm{~g}$. (S.D. 0.25 ), found by McArdle (1957) in a group of 71 patients with neurological diseases. Eliminating from this group of seven those patients in whom a disturbance of pyruvate metabolism might exist, the upper limit of normality is probably about $1.10 \mathrm{mg}$./100 g.; a level above this was found on one occasion (1.22 mg./100 g.).

Interpretation of the $\alpha$-ketoglutarate results is difficult owing to the minute amount present in cerebrospinal fluid (McArdle, 1957) but no obvious abnormality was apparent.

Correlation of the Biochemical Findings and Clinical State.-The importance to be attached to the finding of a disorder of oxidative metabolism will be the greater if the abnormality can be shown to bear a relation to the activity of the disease. Unfortunately the assessment of activity in multiple sclerosis can be extremely difficult, for the clinical manifestations of a plaque depend almost entirely on its site, and it is well known that many active lesions are clinically silent. None the less the clinical approach is still the least unsatisfactory measure of activity. The results of the tests have therefore been grouped, depending on the interval between the test and the last clinical episode. The dates are given in Table $\mathrm{V}, \mathrm{A}$, the results of the abnormal pyruvate tolerance tests being subdivided into two groups depending on whether the highest pyruvate value by the method of Friedemann and Haugen (1943) rose above $1.5 \mathrm{mg} . / 100 \mathrm{~g}$. It can be seen that there is apparently no correlation between activity and an abnormal pyruvate response.
TABLE V

ANALYSIS OF RESULTS IN RELATION TO THE ACTIVITY OF THE DISEASE

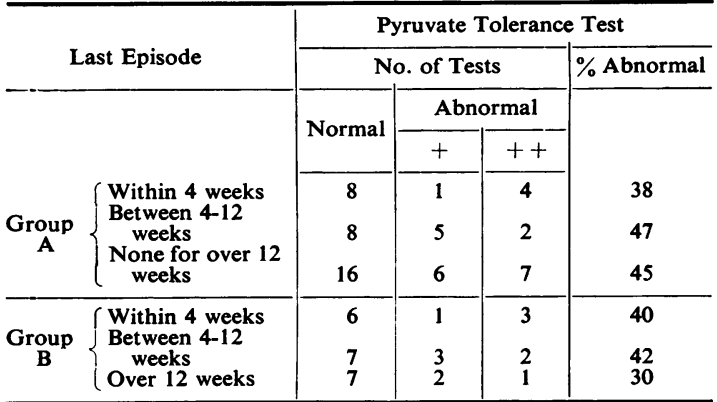

The results of all the tests performed have been classified in relation to the apparent activity of the disease, $A$ in all cases, $B$ in those patients with little or no spasticity (see Table VI) or malnutrition. Abnormal tests have been graded ++ or + according to whether the maximum pyruvate was above or below $1.5 \mathrm{mg} . / 100 \mathrm{~g}$.

It is well known that muscular activity can cause an elevation of the blood pyruvate, so it seemed likely that spasticity might be responsible for the abnormalities in the pyruvate tolerance tests, a hypothesis that had been previously advanced by Bauer (1956). The patients were therefore grouped according to the degree of spasticity (Table VI). Seven out of 19 cases $(36.8 \%)$ with moderate or marked spasticity had a considerable abnormality of pyruvate metabolism, whereas only one out of the 22 patients with little or no spasticity showed a similar degree of impairment.

An obvious possible cause for some of the abnormal pyruvate responses might be vitamin deficiency resulting from poor nutrition. However, there was no reason whatever to expect poor nutrition in these cases, with the exception of four patients in all of whom the blood pyruvate rose after glucose to levels well above the range of normality, the maximal

TABLE VI

ANALYSIS OF RESULTS IN RELATION TO DEGREE OF SPASTICITY

\begin{tabular}{|c|c|c|c|c|c|}
\hline \multirow{2}{*}{\multicolumn{2}{|c|}{ Spasticity }} & \multicolumn{4}{|c|}{ Pyruvate Tolerance Test } \\
\hline & & \multicolumn{3}{|c|}{ No. of Cases } & \multirow[t]{2}{*}{$\%$ Abnormal } \\
\hline & & \multirow{2}{*}{ Normal } & \multicolumn{2}{|c|}{ Abnormal } & \\
\hline & & & + & ++ & \multirow[b]{2}{*}{$\begin{array}{l}25 \\
20 \\
68\end{array}$} \\
\hline Group A & 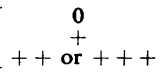 & $\begin{array}{l}9 \\
8 \\
6\end{array}$ & $\begin{array}{l}2 \\
2 \\
6\end{array}$ & $\begin{array}{l}1 \\
0 \\
7\end{array}$ & \\
\hline Group B & $\stackrel{0}{+}++$ or +++ & $\begin{array}{l}3 \\
2 \\
4\end{array}$ & $\begin{array}{l}1 \\
1 \\
4\end{array}$ & $\begin{array}{l}1 \\
0 \\
6^{*}\end{array}$ & $\begin{array}{l}38 \\
71\end{array}$ \\
\hline
\end{tabular}

*Four of these were poorly nourished.

The results of initial tests have been classified in relation to the degree of spasticity present. $A$ in all cases. $B$ in those in whom the disease was apparently inactive. Abnormal tests have been graded ++ or + according to whether the maximum pyruvate was above or below $1.5 \mathrm{mg} . / 100 \mathrm{~g}$. 
levels being $2 \cdot 18,1 \cdot 69,1 \cdot 59$, and $1.54 \mathrm{mg} . / 100 \mathrm{~g}$. One of these patients was a woman of 51 years who had had a partial gastrectomy and had been living on a rather inadequate diet since. The other three patients were all afflicted with severe trigeminal neuralgia as a complication of multiple sclerosis and had all been taking a liquid diet for some months. In addition they all had moderate or severe spasticity, but in one case at least this is unlikely to have been the main cause of the pyruvate abnormality, since a second test, following relief of pain by a medullary tractotomy and a return to a normal diet, gave a maximum rise of $1.28 \mathrm{mg} . / 100 \mathrm{~g}$. as compared with the pre-operative rise to $2.18 \mathrm{mg} . / 100 \mathrm{~g}$. It was not possible to assess the effects of vitamin therapy alone on these patients, since immediate relief of their pain was clearly indicated, but further support for the nutritional origin of the pyruvate abnormality in these three cases was obtained by performing pyruvate tolerance tests on two cases of "idiopathic" trigeminal neuralgia; both showed impaired pyruvate metabolism (maximum pyruvate levels 1.62 and $1.87 \mathrm{mg} . / 100 \mathrm{~g}$.).

It is clear therefore that the presence of spasticity or of malnutrition might have obscured a correlation of activity with impairment of pyruvate metabolism. All the tests that have been done on those patients with little or no spasticity and without evidence of malnutrition have been reexamined with this point in mind, but even though all the tests performed have been included, the numbers are too small to warrant statistical treatment (Table $\mathrm{Vb}$ ). Nine of the 22 tests performed on 14 patients within three months of clinical activity were abnormal. There was marked impairment in five tests and it is noteworthy that these were all obtained on two patients. These two patients had serial tests performed over periods of four and 12 months (Table VII). Neither had spasticity, but during these times both experienced characteristic exacerbations of the disease, varying in severity and followed by complete or partial re-

TABLE VII

RESULTS OF PYRUVATE TOLERANCE TESTS PERFORMED DURING PHASES OF APPARENT QUIESCENCE AND ACTIVITY IN TWO PATIENTS WITH MULTIPLE SCLEROSIS

\begin{tabular}{|c|c|c|c|c|c|}
\hline \multirow[b]{3}{*}{ Case 1} & \multirow{2}{*}{ Date of Test } & \multirow{2}{*}{$\begin{array}{l}\text { Degree } \\
\text { of } \\
\text { Activity }\end{array}$} & \multicolumn{3}{|c|}{ Blood Pyruvate (mg./100 g.) } \\
\hline & & & $0 \mathrm{~min}$. & $60 \mathrm{~min}$. & $90 \mathrm{~min}$. \\
\hline & $\begin{array}{r}13.10 .54 \\
19 \cdot 11.54 \\
23.11 .54 \\
9.9 .55 \\
6.10 .55\end{array}$ & $\begin{array}{l}\text { Slight } \\
\text { Marked } \\
\text { Marked } \\
\text { Marked } \\
\text { Quiescent }\end{array}$ & $\begin{array}{l}0.49 \\
0.98 \\
0.83 \\
1.47 \\
0.63\end{array}$ & $\begin{array}{l}1.06 \\
1.70 \\
1.36 \\
2.52 \\
1.34\end{array}$ & $\begin{array}{l}0.70 \\
1 \cdot 27 \\
1 \cdot 36 \\
2 \cdot 10 \\
1 \cdot 18\end{array}$ \\
\hline$\overline{\text { Case } 2}$ & $\begin{array}{r}10.12 .54 \\
4.1 \\
7.55 \\
29.3 .55 \\
3.55\end{array}$ & $\begin{array}{l}\text { Quiescent } \\
\text { Marked } \\
\text { Marked } \\
\text { Quiescent }\end{array}$ & $\begin{array}{l}1.03 \\
0.77 \\
1.44 \\
0.86\end{array}$ & $\begin{array}{l}1.07 \\
1.88 \\
1.95 \\
1.17\end{array}$ & $\begin{array}{l}1.22 \\
1.48 \\
1.51 \\
1.75\end{array}$ \\
\hline
\end{tabular}

missions. These results could be interpreted as providing suggestive evidence of an association between activity of the disease and impairment of pyruvate metabolism, but, at the other extreme, a test performed on a patient at the height of an exceptionally intense and widespread relapse was completely normal.

\section{Discussion}

The existence of an abnormality of pyruvate metabolism in some cases of multiple sclerosis seems reasonably certain, since in about half the cases investigated the pyruvate level has risen above the normal range after glucose, and the mean levels at 60 and $90 \mathrm{~min}$. have been significantly higher than the mean levels of healthy control subjects. These results largely confirm the findings of previous workers, though, like Henneman et al. (1954) and Bauer (1956), we have been unable to demonstrate any significant elevation in the resting level of the blood pyruvate. Most previous workers have assumed that the abnormal rise in $\alpha$-keto acids shown by the somewhat unspecific Friedemann and Haugen (1943) technique has been due to pyruvic acid, and although Henneman et al. (1954) used the chromatographic technique, the point remained uncertain since there was no significant difference between the mean increase in their four patients and in their normal controls. We have now shown that this assumption was in fact correct, since in all the cases showing an abnormal rise in $\alpha$-keto acids, as judged by the simpler technique, there was also a parallel and equally abnormal rise in pyruvic acid.

It has also been shown that those cases which showed by chromatographic methods an abnormal rise in pyruvate after glucose, also showed a mean elevation of $\alpha$-ketoglutarate that is significantly different both from that of the normal controls and of the other patients. It is possible that the fasting level of $\alpha$-ketoglutarate may also have been raised as had previously been reported by Henneman et al. (1954), but our finding that these levels are higher in females than in males makes the fasting levels difficult to evaluate. This difficulty, however, does not arise in the interpretation of the rise following glucose, since this was the same in the two sexes.

A further significant finding in the group with abnormal pyruvate response has been the low fasting level of the plasma citrate, in contrast to the normal mean level in the other patients. Jeanes and Cumings (1958) did not find any significant difference between the citric acid levels of their active and inactive cases of multiple sclerosis, but if the fasting values of Henneman et al. (1954) are averaged a figure $(1.58 \mathrm{mg} . / 100 \mathrm{ml}$.) is obtained that 
is close to that found in our group with abnormal pyruvate metabolism and different from the value of $2.34 \mathrm{mg}$. $/ 100 \mathrm{ml}$. found in their normal controls. On the other hand, our cases have not shown any significant differences as regards the behaviour of the plasma citrate after glucose in contradistinction to Henneman et al. (1954) who noted a small rise rather than a fall in citrate, and to Jeanes and Cumings (1958) who found that the citrate level frequently rose after the ingestion of glucose, although the mean level at $60 \mathrm{~min}$. was unchanged and the mean rise at 90 min. was minimal.

The changes in $\alpha$-ketoglutarate after glucose and the low fasting level of the plasma citrate in those cases which also showed an abnormality of pyruvate metabolism are consistent with a partial or relative impairment of the very similar enzyme systems concerned with pyruvate and $\alpha$-ketoglutarate utilization. Analysis of the cases, however, suggests that the abnormality or abnormalities of the Krebs cycle that have been found in multiple sclerosis may arise from factors, such as spasticity and malnutrition, which are not directly related to the disease. There remain a few patients who, in the absence of obvious complicating factors, have shown impairment of pyruvate metabolism while in the active phase of the disease. None the less it is difficult to believe that the pyruvate disturbance is more than a complication, since intense and widespread activity need not be accompanied by any demonstrable abnormality of the Krebs cycle.

\section{Summary}

Pyruvate has been estimated by the Friedemann and Haugen (1943) method in the blood of 41 patients with multiple sclerosis. The fasting levels were normal, but in 18 patients the level rose above the normal range following the ingestion of glucose.

A similar abnormal rise occurred in seven out of 20 patients in whom the pyruvate was determined by a chromatographic method. These seven patients also showed an abnormal rise in $\alpha$-ketoglutarate after the ingestion of glucose and had low fasting plasma citrate levels.

The resting level of blood $\alpha$-ketoglutarate was higher in females than in males.

The cerebrospinal fluid pyruvate was normal in 12 patients with multiple sclerosis.

The abnormalities in pyruvate metabolism were more closely correlated with complications such as spasticity and malnutrition than with activity.

It is concluded that a disturbance of pyruvate metabolism is unlikely to be causally related to the disease.

We are much indebted to the Medical Research Council for support for this investigation,'to Sir Charles Symonds and Dr. M. J. McArdle for allowing us access to their patients, to Professor R. H. S. Thompson for helpful advice, and to Miss $\mathrm{H}$. Pels for her skilled technical assistance.

\section{REFERENCES}

Bauer, H. (1956). Biochem. Z., 327, 491

Ervenich, P. (1952). Atrzl. Prax., Lpz., 4, 2.

- (1953). Atrzl. Forsch., 7, 55.

Friedemann, T. E., and Haugen, G. E. (1943). J. biol. Chem., $147,415$.

Henneman, D. H., Altschule, M. D., Goncz, R. M., and Alexander, L. (1954). A.M.A. Arch. Neurol. Psychiat., 72, 688.

Jeanes, A. L., and Cumings, J. N. (1958). Confin. neurol. (Basel), 18, 397.

Joiner, C. L., McArdle, B., and Thompson, R. H. S. (1950). Brain,

Jones, H. H., Jones, H. H. Jr., and Bunch, L. D. (1950). Ann. intern. Med., 33, 831 .

McArdle, B. (1955). Biochem. J., 60, 647.

(1957). Ibid., 66, 144

Sercl, M., and Johnová, B. (1956). Confin. neurol. (Basel), 16, 177. Weil-Malherbe, H., and Bone, A. D. (1949). Biochem. J., 45, 377. 